\title{
Transição de Carreira em Adultos Brasileiros: um Levantamento da Literatura Científica
}

\section{Career Transitions in Brazilian Adults: a Review of Scientific Literature}

\author{
Daniela Bach Rizzatti', Adriana Malheiros Sacramento2, Viviane de Souza \\ Valmorbida 3 , Viktoria Pereira Mayer ${ }^{4}$, Manoela Ziebell de Oliveira ${ }^{5}$
}

Resumo

Este estudo objetivou apresentar um levantamento da produção científica nacional sobre transição de carreira em adultos. Por meio das bases de dados Science Direct, SciELO e Periódico Capes, foram selecionados 10 artigos publicados no Brasil entre os anos 2000 e 2015. Os textos selecionados foram analisados segundo cinco aspectos: ano de publicação, desenho metodológico, amostra, objetivo e principais achados. Os artigos analisados abordam dois principais tipos de transição: da universidade-trabalho e mercado-mercado. Os resultados mostraram a importância do planejamento da carreira e do conhe-cimento do mercado de trabalho durante o processo de transição de carreira em adultos. Também indicaram que a transição é um momento de reflexão e de autoconhecimento que exige importantes tomadas de decisões. Por fim, apontaram a escassez de publicações sobre transições de carreira não planejadas, como demissões involuntárias. Palavras-chave: Transição de carreira. Desenvolvimento profissional. Revisão de Literatura. Adultos.

\section{Abstract}

This study presents a review of the Brazilian scientific literature regarding career transition among adults. We selected 10 articles published between the years 2000 and 2015 from the Science Direct, SciELO and Periódico Capes databases. The selected texts were analyzed according to five aspects: publication year, methodological design, sample, study objective and primary findings. The articles analyzed approached two main transitions: from university to the job market and inside the job market. The results showed the importance of career planning, as well as the knowledge of the labor market, during adults' career transition processes. Furthermore, the findings indicate that the transition is a time of reflection and self-

\footnotetext{
${ }^{1}$ Pontifícia Universidade Católica do Rio Grande do Sul, Porto Alegre, Brasil. E-mail: danibachrizzatti@gmail.com

${ }^{2}$ Universidade Federal do Rio Grande do Sul, Porto Alegre, Brasil. E-mail: adriana.msacramento@gmail.com

${ }^{3}$ Pontifícia Universidade Católica do Rio Grande do Sul, Porto Alegre, Brasil. E-mail: viviane.svalmorbida@gmail.com

${ }^{4}$ Pontifícia Universidade Católica do Rio Grande do Sul, Porto Alegre, Brasil. E-mail: viktoriapereiramayer@gmail.com

${ }^{5}$ Pontifícia Universidade Católica do Rio Grande do Sul, Porto Alegre, Brasil. E-mail: manoela.ziebell@gmail.com
} 
knowledge, which requires making important decisions. Finally, the results point to the scarcity of publications on unplanned career transitions, such as involuntary dismissals.

Keywords: Career transition. Professional development. Literature review. Adults 


\section{Introdução}

Transição de carreira é um tema que propicia inúmeras reflexões a partir do entendimento de situações enfrentadas por indivíduos em diferentes momentos da vida, sendo elas planejadas ou não. Por se tratar de uma experiência compartilhada por pessoas nos mais variados contextos, trata-se de um tema fértil e passível de investigação científica e produção de conhecimento. Por isso o debate sobre esse assunto é de suma importância, especialmente nos dias de hoje e no cenário nacional, uma vez que muitos indivíduos têm empreendido trocas de emprego e carreira em razão do contexto econômico do Brasil, caracterizado por incertezas, como pode ser ilustrado pelos dados da pesquisa realizada pelo Departamento Intersindical de Estatística e Estudos Socioeconômicos (Dieese) em 2014. Os resultados apontam que a taxa de rotatividade no mercado de trabalho brasileiro alcançou $62,8 \%$ em 2014 (entre 2003 e 2007 a média foi de 54\% no segmento de celetistas), tendo os pedidos de desligamento pelo trabalhador representado quase $25 \%$ do total. O indicador de rotatividade envolve admissões e desligamentos, com especial atenção às movimentações no setor privado, no qual os trabalhadores não têm estabilidade no emprego. Ainda de acordo com os dados, em 2014 o mercado celetista registrou 65,8 milhões de posições de empregos e, ao fim do ano, contava com 40,6 milhões de postos de trabalho ativos (Dieese, 2014). Dados complementares do Instituto Brasileiro de Geografia e Estatística (IBGE) indicam que os valores compostos da subutilização da força de trabalho (taxas de desocupação por insuficiência de horas e da força de trabalho potencial) no Brasil, em 2016, foi de 21,2\%, atingindo 22,9 milhões de pessoas, o que significa um incremento de 20,9\% em relação a meses anteriores e de $18 \%$ em relação ao mesmo período de 2015.

De acordo com Savickas (2012), mudanças econômicas rápidas e frequentes enfrentadas pela sociedade, como as descritas, resultam em transformações na relação entre trabalho e carreira. Esta, segundo o autor, deixou de ser um caminho linear, passando a ser uma representação das decisões tomadas pelos indivíduos nos contextos de suas vidas e nos ambientes nos quais estão inseridos. Igualmente, segundo Magalhães (2013), a carreira se dá a partir de uma sequência de trabalhos, ocupações e profissões articulados no decorrer da vida, dando ao conceito uma ideia de temporalidade.

Tendo em vista o contexto apresentado, o objetivo do estudo é realizar uma revisão de literatura a respeito das transições de carreira em adultos que contemplem a realidade brasileira. Assim, este estudo tem por objetivo apresentar artigos brasileiros sobre transição de carreira em adultos a fim de realizar uma avaliação crítica sobre os principais avanços teóricos e práticos, além de uma agenda para futuras investigações sobre o tema. Inicialmente, será introduzido fundamentos teóricos sobre a temática para fundamentar a discussão da presente pesquisa. 
Atualmente, a carreira pode ser definida como a atribuição de significados pelos indivíduos aos seus comportamentos vocacionais e suas experiências ocupacionais. O conceito envolve, portanto, não apenas uma dimensão objetiva, que é traduzida pela sequência de experiências ocupacionais ao longo da vida do indivíduo, mas também apresenta uma dimensão subjetiva, a qual remete ao modo como essas experiências são organizadas pela pessoa, de forma a produzir uma história com significado (Savickas, 2013). A definição apresentada teve origem na teoria construtivista de carreira e passou por diversos aprimoramentos ao longo do tempo. Sua origem remonta aos estudos de Donald Super, que tiveram início na década de 1950.

Donald Super, pioneiro em pesquisas sobre desenvolvimento de carreira, propôs, na década de 1980, o modelo Life-Span, Life-Space (Super, 1980). Life-Span se refere ao desenvolvimento de carreira por meio de tarefas evolutivas específicas, relacionadas às expectativas sociais, bem como às expectativas do próprio indivíduo, que quando transformadas em metas e em objetivos envolvem processos adaptativos. Já a dimensão Life-Space remete aos diversos papéis que os indivíduos ocupam ao longo de sua vida e que estão relacionados às tarefas evolutivas realizadas (Bedin, Sarriera, \& Paradiso, 2013). Tais tarefas dizem respeito aos estágios de desenvolvimento de carreira: crescimento, exploração, estabelecimento, manutenção e desengajamento ou desaceleração, que remetem às etapas do desenvolvimento humano cronológico. O crescimento corresponde ao período da infância e parte da adolescência; a exploração à adolescência e ao início da vida adulta; o estabelecimento à vida adulta; a manutenção refere-se à adultez madura, e o desengajamento está associado ao preparo para a aposentadoria. Ao longo do seu desenvolvimento, os indivíduos enfrentam transições de carreira relacionadas às diferentes etapas de vida. $\mathrm{Na}$ adolescência, costumam ocorrer transições da escola para a universidade ou para o mercado de trabalho; e na idade adulta, transições dentro do próprio mercado de trabalho (ou seja: deixando uma forma de ocupação como um trabalho, emprego, projeto ou área, por exemplo, e adquirindo uma nova forma de ocupação). Nos adultos, as transições, com muita frequência, podem ser antecipadas pelos indivíduos, conforme a sua clareza de autoconceito e conhecimento sobre a realidade do mundo do trabalho (Super, Savickas, \& Super, 1996).

Essa articulação teórica proporciona a base para a compreensão da realidade complexa das transições de carreira. Um profissional de meia idade, por exemplo, estaria (cronologicamente) em estágio de estabelecimento, mas, ao iniciar uma transição de carreira, deverá fazê-lo por um estágio de exploração, no qual necessitará novamente rever seu autoconceito e as possibilidades no mundo do trabalho. Nesse ponto, cabe ressaltar que o autoconceito é o construto central nessa teoria, pois é o ponto de partida para formação de interesses, valores e características pessoais que nortearão as escolhas. Assim, os indivíduos formam redes de autoconceitos diversas e específicas, como o autoconceito vocacional, que se 
relaciona às preferências profissionais (Super et al., 1996).

No atual momento de instabilidade da economia e do mercado, os percursos de carreira deixaram de ser lineares e previsíveis e cada vez mais dependem das escolhas do próprio indivíduo, o que pode ampliar o número de transições de carreira ao longo da vida profissional, obrigando as pessoas a assumirem maior responsabilidade pela gestão de sua carreira e adaptarem-se a novas estratégias de planejamento (Savickas \& Baker, 2005). A necessidade de adaptação e responsabilização pela própria carreira provoca a preocupação e o envolvimento com as tarefas de desenvolvimento de carreira descritas nos parágrafos anteriores, as quais possibilitam aprofundar o autoconhecimento e clarear autoconceitos, tornando os indivíduos capazes de tomar decisões mais adequadas e apropriadas sobre quem são e o que almejam fazer em suas vidas (Schreiner, 2012).

Autores como Ambiel (2014) e Savickas (2013) vêm se dedicando a pesquisar esse estado de prontidão dos indivíduos para lidarem com as mudanças, além das atitudes e estratégias utilizadas pelas pessoas para anteciparem dificuldades e, igualmente, prepararem-se para enfrentá-las, recursos que chamam de adaptabilidade de carreira (Savickas, 2013). Esse construto, proposto por Super, foi definido originalmente como maturidade para escolha profissional. Posteriormente, ao perceber que ele não era adequado para entender o desenvolvimento de carreira em adultos, o autor propôs o termo adaptabilidade de carreira, que vem sendo utilizado também na compreensão do processo na adolescência e adultez (Savickas, 1997). No entanto, somente mais recentemente, na última década, Savickas tem aprimorado o construto a partir da criação de um instrumento e produção de evidências empíricas, dando ênfase à adaptabilidade na sua teoria da construção da carreira (Savickas, 2013).

Ainda a respeito da adaptabilidade de carreira, é importante destacar que se trata de um construto multidimensional, o qual é caracterizado pela forma como os indivíduos lidam com as mudanças por meio de quatro dimensões. São elas: preocupação (antecipação do futuro), curiosidade (busca de informações sobre si mesmo e sobre o mundo do trabalho), controle (percepção da responsabilidade de cuidar da própria carreira) e, por fim, confiança (sentimento de competência para enfrentar os desafios envolvidos nas tarefas evolutivas), de acordo com Savickas (2002).

A teoria do desenvolvimento proposta por Super vem sendo aprimorada por Mark Savickas, que a tem direcionado cada vez mais para uma perspectiva construtivista, por acreditar que a carreira depende, especialmente, do indivíduo que a constrói. Assim, surge também a noção de carreira subjetiva, a qual é construída por atribuições de significados dados pelos sujeitos para as suas experiências pessoais (Savickas, 2013). Tal posicionamento vai ao encontro do que afirmam estudiosos dos movimentos e modelos de carreira observados e produzidos nas últimas décadas (Baruch, Szűcs \& Gunz, 2015), os quais enfatizam o papel de agência dos profissionais. 
A partir do referencial teórico citado, temos subsídios para compreender a complexidade do contexto e alguns recursos que os indivíduos podem utilizar em seus processos de transição. Já no que tange à concepção desses processos, Levinson (1977) descreve as transições como pontos de virada entre dois períodos de maior estabilidade. Schlossberg, Waters e Goodman (1995), por sua vez, afirmam tratar-se de um processo que provoca alterações na vida do indivíduo, as quais requerem novos comportamentos, estratégias e perspectivas. Segundo os autores, para compreender o significado de uma transição, é necessário reconhecer seu tipo, o contexto em que ocorre e o impacto que provoca na vida dos indivíduos. Mais especificamente, Schlossberg (1981, p. 5) afirma tratar-se de: "[...] evento ou não-evento que resulta numa mudança de concepção sobre si mesmo e o mundo, portanto requer uma mudança correspondente em seu comportamento e relacionamentos". Para a autora, portanto, a transição é compreendida a partir das dificuldades e dos sentidos atribuídos à vivência das mudanças, dos recursos que os indivíduos utilizam e da forma como se ajustam a ela. Os recursos e as estratégias, para Schlossberg (1989), são aprendidos por meio de processos cognitivos que permitem controlar e gerenciar as transições, inclusive não planejadas, fortalecendo os recursos dos quais o indivíduo dispõe, ressignificando-os ou criando novos.

Tendo em vista os construtos apresentados, é possível compreender que a construção da carreira no contexto atual é um processo contínuo e de mudanças frequentes. Sendo assim, é necessário identificar como as pessoas enfrentam as transições pelas quais decidem ou necessitam passar. Com o objetivo de contribuir para essa reflexão, o presente estudo analisará artigos brasileiros sobre transições de carreira de adultos, a fim de sintetizar as variáveis relacionadas à transição de carreira que estão ganhando a atenção dos pesquisadores hoje, bem como identificar futuras agendas de pesquisa. Espera-se, com os resultados deste levantamento, apresentar reflexões importantes sobre a temática, tais como: controle sobre a carreira, recursos utilizados, fatores influenciadores e as tomadas de decisões durante o processo de transição de carreira. O intuito é auxiliar profissionais da área de orientação profissional e de aconselhamento de carreira, bem como gestores de pessoas, a orientarem e administrarem profissionais que estejam passando por processos de transição.

\section{Método}

Foi realizado um estudo de levantamento com o objetivo de identificar, analisar e descrever o conhecimento sobre transições de carreira produzido no Brasil. Para isso, realizou-se a busca de artigos pela expressão "transição de carreira" nas bases Science Direct, Periódicos Capes e SciELO, as quais foram selecionadas por serem referências para a busca de artigos nacionais. A busca de artigos ocorreu no mês de agosto de 2016 e teve como critérios de inclusão que: estivessem disponível de forma integral (com acesso aberto nas bases pesquisadas) ou fossem disponibilizados 
pelo autor em formato digital; estivessem escritos em língua portuguesa e fossem de origem brasileira. Teses, dissertações e demais produções foram excluídas da busca.

Inicialmente, 15 artigos foram encontrados na base Science Direct, 40 artigos na base Periódicos Capes e 21 artigos na base SciELO, sendo um total de 76 artigos selecionados na primeira busca. Posteriormente, procedeu-se à leitura integral dos resumos a fim de certificar-se de que os artigos atendiam aos critérios de inclusão do estudo. Nesta etapa, foram excluídos artigos cujo tema central não eram as transições de carreira e os que não eram brasileiros. Após a etapa descrita, 66 artigos foram excluídos: 42 não abordavam o tema central da revisão e 24 artigos eram repetidos entre as bases. No fim, 10 artigos atenderam a todos os critérios e foram analisados, classificados e tabulados segundo as categorias: ano de publicação, desenho metodológico e amostra; objetivo e resultados; transição universidade-mercado e transição mercado-mercado. A Figura 1 apresenta as etapas do processo de seleção dos artigos para análise.

Figura 1. Etapas do estudo de revisão de literatura

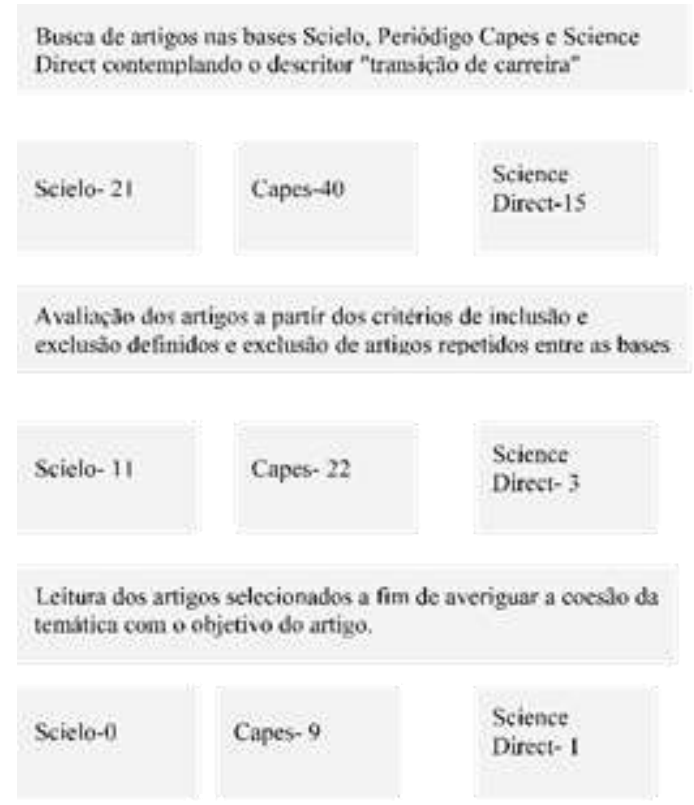

Fonte: Criada pelas autoras.

\section{Resultados}

Ano de Publicação, Desenho Metodológico e Amostra

A primeira publicação encontrada foi no ano de 2000 (10\%). Embora a presente revisão não tenha estabelecido limites temporais para a inclusão de artigos na amostra, é possível supor que o interesse pela investigação das transições de carreira de adultos esteja atrelado ao contexto de imprevisibilidade e mudanças no mundo do 
trabalho ocorrido especialmente após a revolução tecnológica dos anos 1990. Desse período até por volta dos anos 2000, verificou-se a abertura econômica do Brasil, marcada entre outros aspectos por oferta crescente de mão de obra (decorrente de desligamentos e novos ingressos no mercado de trabalho), que estimulou as transições voluntárias de profissionais em diversos setores da economia (Pauli, Nakabashi, \& Sampaio, 2012) e reforçou a ideia da carreira autogerenciada, já presente em outros países (Balassiano, 2006; Baruch, 2015).

Houve publicação de apenas um artigo em cada ano em 2005, 2010 e 2011. Em 2013 três artigos (30\%) e em 2014 dois artigos foram publicados (20\%), mostrando uma relativa estabilidade da produção sobre o tema. Por fim, entre 2015 e a data da pesquisa, apenas um artigo foi publicado. Essa queda pode ter relação com a crise de demissões observada a partir de 2014, a qual restringiu as transições previsíveis no mercado e pelos pesquisadores.

Dentre os analisados, cinco eram artigos qualitativos, três quantitativos, 1 longitudinal qualitativo e 1 descritivo quantitativo. As amostras de pesquisa qualitativa foram compostas por 22 professores universitários, cinco profissionais em diferentes níveis de gerência na empresa que estavam em busca de transição de carreira mercado-mercado e, também, sete alunos que participaram da aula de orientação e planejamento de carreira e seis estudantes de engenharia, todos estavam se formando na universidade e inserindose no mercado de trabalho. Já para as pesquisas quantitativas, o número de participantes que compuseram as amostras foi superior. Foram no total 445 indivíduos adultos enfrentando ou buscando uma transição de carreira e 253 universitários no último ano da graduação.

Em relação à descrição metodológica quantitativa descritiva, que é realizada por meio do estudo, da análise, do registro e da interpretação dos fatos do mundo físico sem que ocorra a interferência do pesquisador (Barros \& Lehfeld, 2007), verificou-se apenas um artigo, que utilizou 41 tenistas profissionais para análise. E, por fim, em relação ao estudo longitudinal qualitativo, que consiste em estudar um processo ao longo do tempo para investigar mudanças, refletindo uma sequência de fatos (Hochman, Oliveira Filho \& Ferreira, 2005), foi encontrado apenas um artigo, com uma amostra de 14 profissionais de Recursos Humanos.

\section{Objetivo e resultados}

O Quadro 1 apresenta uma síntese dos autores e ano das publicações analisadas, seus objetivos e principais resultados. Ao analisá-los, verificou-se que sete artigos abordavam a transição de carreira mercado-mercado e três investigaram o ingresso de universitários no mercado de trabalho. Assim, os tipos de transição abordados nos artigos selecionados são agrupados e nomeados em duas categorias: transição da universidade-mercado e transição mercado-mercado. As transições de carreira no primeiro caso se deram tanto de forma esperada como não planejada, fato que não ocorre no segundo, pois o ingresso no mercado de 
trabalho após a conclusão de um curso superior é esperado e normativo. Transições planejadas se caracterizam pela ciência do profissional, que pode se preparar para a mudança. Transições inesperadas, por sua vez, são mais complexas, pois não há chance de se preparar para o evento (Schlossberg, 1989).

Quadro 1. Publicações analisadas

\begin{tabular}{|c|c|c|c|}
\hline Autores & Ano & Objetivo & Principais achados \\
\hline $\begin{array}{l}\text { Kilimnik \& } \\
\text { Rodrigues }\end{array}$ & 2000 & $\begin{array}{l}\text { Compreender como se deram } \\
\text { as demissões de profissionais } \\
\text { de } \mathrm{RH} \text {, as trajetórias que se } \\
\text { delinearam após a demissão e } \\
\text { as âncoras de carreiras que as } \\
\text { nortearam. }\end{array}$ & $\begin{array}{l}\text { O fato de passar por uma transição de } \\
\text { carreira contribuiu para mudança de postura. } \\
\text { Os profissionais passaram a se empenhar } \\
\text { mais, o que proporcionou crescimento } \\
\text { profissional, ampliação de conhecimentos e } \\
\text { habilidades, além de maior satisfação com o } \\
\text { trabalho, independentemente de ser } \\
\text { assalariado ou autônomo. }\end{array}$ \\
\hline $\begin{array}{l}\text { Vasconselos, } \\
\text { Andrade, Neiva } \\
\text { de Lima \& } \\
\text { Viana }\end{array}$ & 2005 & $\begin{array}{l}\text { Verificar os principais } \\
\text { determinantes da transição de } \\
\text { tenistas juvenis brasileiros para } \\
\text { o circuito profissional. }\end{array}$ & $\begin{array}{l}\text { Para facilitar a passagem de tenistas juvenis } \\
\text { para o circuito profissional, ajudas externas } \\
\text { se fazem necessárias, como: apoio de } \\
\text { empresas e aumento no número de torneios } \\
\text { profissionais no país. }\end{array}$ \\
\hline $\begin{array}{l}\text { Edite, Tavares, } \\
\text { Penna \& Soares }\end{array}$ & 2010 & $\begin{array}{l}\text { Examinar percepç̃oes de } \\
\text { alunos sobre a disciplina } \\
\text { optativa de Orientação e } \\
\text { Planejamento de Carreira } \\
\text { oferecida em uma universidade } \\
\text { federal para alunos em } \\
\text { conclusão de curso. }\end{array}$ & $\begin{array}{l}\text { A disciplina promove socialização e permite } \\
\text { que os jovens falem sobre as angústias do } \\
\text { processo de inserção profissional. Eles } \\
\text { buscam a disciplina para obterem } \\
\text { autoconhecimento e informações sobre } \\
\text { processos seletivos. Avaliam positivamente a } \\
\text { disciplina e tecem críticas ao academicismo } \\
\text { de alguns professores que orientam os } \\
\text { universitários apenas para a Academia. }\end{array}$ \\
\hline
\end{tabular}


Veloso \& Dutra 201

Silva \& Teixeira
Identificar como carreiras sem

fronteiras se manifestam no

autogerenciamento da

transição de carreira dos

participantes.

Compreender como

experiências de estágio

contribuem para o

desenvolvimento da

adaptabilidade de carreira e

para a transição de estudante a profissional.
A maneira como a pessoa gerencia sua carreira enquanto trabalha na empresa influencia o autogerenciamento da transição profissional e também a manifestação das carreiras sem fronteiras. Não foi possível observar um padrão para essa manifestação durante a transição.

As experiências de estágio influenciam o desenvolvimento da adaptabilidade de carreira, especialmente nas dimensões de curiosidade e confiança. Várias características dos estágios mostraram-se relacionadas ao desenvolvimento de carreira, revelando sua importância para o processo de transição do papel de estudante para o de profissional.

A elaboração de uma imagem positiva e idealista de si e da atividade docente para uma visão negativa das instituições de ensino em oposição à imagem positiva e séria do mundo organizacional; constatação de que o alto nível de pressão por resultados e por competência levou os profissionais, competentes mas tolhidos pelo excesso de exigências, à transição de carreira.

Lócus de controle, apoio social e necessidade financeira foram os melhores preditores dos comportamentos de busca de emprego. Indivíduos que priorizaram a estabilidade no emprego apresentaram maior necessidade financeira, externalidade 
de controle e maior frequência de busca de emprego.

Soares,

Francischetto,

Dutra, de

Miranda,

Nogueira,

Leme, Araújo \&

Almeida

Ramos \& Joia

2014

Estudar o turn away, entender como e por que os profissionais de TI mudam de área; identificar características típicas dessa transição.

Investigar a migração dos profissionais de TI para outras áreas por meio da identificação dos antecedentes associados à intenção de abandonar essa área.
As expectativas dos ingressantes tiveram correlação com a qualidade das suas vivências acadêmicas. As expectativas de envolvimento nas relações com os colegas, no projeto vocacional de carreira e nas atividades curriculares do curso foram associadas à adaptação acadêmica dos estudantes.

Profissionais de TI desejam mais oportunidades de crescimento do que as empresas conseguem oferecer ou na área técnica. O desejo dos profissionais de TI de mudar de área não está ligado à insatisfação com as atividades, mas sim à busca por atividades interessantes e diferentes e por novos desafios e experiências.

Foram antecedentes estatisticamente significativos da transição para outras áreas: exaustão com o trabalho na TI, insatisfação com a área, necessidade de adquirir novas experiências profissionais para se manter atrativo ao mercado de trabalho, de crescimento profissional, e prévia e consciente capacitação e desenvolvimento gerenciais.

\section{Transição da Universidade para o Mercado}

A transição universidade-mercado é um momento de exploração, em que o indivíduo analisa as oportunidades em sua área de formação, bem como o ambiente em que almeja se inserir (Super, Savickas \& Super, 1996). Também, pode ser 
um processo em que a relevância dos papéis sociais se altera, visto que as tomadas de decisão relacionadas à escolha de curso já são indícios do interesse profissional, ainda que não correspondam a um planejamento definitivo, e sim exploratório (Göks \& Lassance, 1997).

Esse tipo de transição pode ser conflitante, uma vez que as exigências do mercado estão mais intensas e somente o diploma não é mais a certeza de inserção profissional. Uma transição bemsucedida depende também do grau de comprometimento da pessoa com sua carreira e da competência para explorar e conhecer oportunidades disponíveis (Lassance \& Sparta, 2003). A conclusão do curso implica ainda em uma reavaliação de experiências já vivenciadas, especialmente nos estágios, os quais influenciam de forma positiva o desenvolvimento da adaptabilidade de carreira, auxiliando também na autoeficácia e no autoconceito (Silva \& Teixeira, 2013).

É isso que mostra o estudo qualitativo analisado nesta pesquisa realizado por Silva e Teixeira (2013), que entrevistaram seis formandos de um curso de Engenharia Civil com o objetivo compreender de que forma os estágios durante a faculdade podem contribuir para $\mathrm{O}$ desenvolvimento da adaptabilidade de carreira e como podem auxiliar no processo de transição para o mercado de trabalho. Os resultados indicaram ainda que as dimensões da adaptabilidade (curiosidade e confiança) foram mais associadas às experiências de estágio e à preparação para transição ao papel de profissional, uma vez que são momentos que pressupõem a busca por aprendizado, autoconhecimento e conhecimento de mercado. Os participantes salientaram, também, que os estágios ajudaram na experiência e no preparo para enfrentar o mercado de trabalho, pois se sentiam mais responsáveis e autônomos. Os autores apontam ainda a importância de promover intervenções com universitários desde o início do percurso a fim de propiciar um espaço de reflexão e oportunidade para construção de um projeto profissional que possa incluir o planejamento da própria experiência acadêmica e preparar melhor o aluno para a transição para o mercado de trabalho.

Em outro estudo analisado nesta revisão, Soares et al. (2014) buscaram identificar o impacto das expectativas iniciais de 182 estudantes ingressantes na adaptação à universidade no primeiro ano de curso. Os resultados indicaram uma correlação entre expectativas iniciais e a qualidade das vivências acadêmicas dos estudantes. Em particular, as expectativas sobre $\mathrm{O}$ relacionamento com os colegas, o projeto profissional e as atividades curriculares do curso. Os autores sugerem que futuras pesquisas sobre a temática incluem outras variáveis como nível socioeconômico e gênero, e também que explorem diferenças entre universidades públicas e particulares.

Na pesquisa feita por Magalhães e Teixeira (2013) com o objetivo de investigar as variáveis pessoais e situacionais vinculadas aos comportamentos de busca de emprego, obteve-se uma amostra de 215 universitários do penúltimo ou último ano de cursos de graduação de duas 
universidades públicas situadas nas regiões Sul e Nordeste do Brasil. Ainda, os resultados indicaram que aspectos financeiros têm forte relação com a busca de emprego, fato que pode influenciar e diminuir os níveis de aspiração em relação aos projetos profissionais para indivíduos que consideraram importante a variável necessidade financeira. Os autores discutem que as diminuições das aspirações profissionais podem estar relacionadas ao resultado das buscas de emprego malsucedidas, o que também pode levar o sujeito a avaliar que o sucesso na busca de emprego depende dos empregadores e da rede de apoio (Magalhães \& Teixeira, 2013).

Os estudantes que priorizam fazer o que gostam, por sua vez, podem apresentar uma visão pouco realista sobre o mercado de trabalho. Desse modo, a situação e o momento pessoal de cada indivíduo, terão importante influência na forma como lidará com a transição profissional. Os autores sugerem que programas de orientação profissional sejam oferecidos para os estudantes de forma a oportunizar um espaço para a construção de um projeto de carreira e um planejamento adequado da inserção no mercado, nos quais os valores associados ao trabalho possam ser incluídos como objetos de intervenção (Magalhães \& Teixeira, 2013).

Os artigos que investigaram amostras de universitários em transição universidade-mercado evidenciaram a relevância, para esse processo, do autoconhecimento, da visão clara e realista do indivíduo sobre si mesmo e da avaliação adequada sobre o mercado de trabalho. O desenvolvimento de carreira, hoje, pode ser compreendido como um processo que possibilita ao ser humano conhecer suas habilidades, seus interesses e seus prazeres no trabalho (Schreiner, 2012). Com base nos artigos apresentados, percebe-se a relevância dos estudos sobre carreira e transições ao longo da vida, e de como esses temas contemplam não apenas o foco no trabalho, mas também as conquistas e os crescimentos pessoais. Os artigos analisados destacam ainda os estágios acadêmicos e as experiências no mundo corporativo como elementos que contribuem na elaboração de recursos para enfrentar as transições profissionais, bem como auxiliam para as tomadas de decisões.

\section{Transição Mercado-Mercado}

Dentre os artigos incluídos nessa categoria, nove tiveram como foco a análise de transições planejadas e apenas um artigo avaliou processos de transições não planejadas. Esses novos artigos enfatizaram a questão do turn-away ou opt-out, conceitos que se referem a transições caracterizadas pelo abandono da área de atuação ou formação original e ocupação de posições em áreas distintas no próprio local de trabalho ou em outras empresas, as quais muitas vezes evoluem para posições gerenciais, possibilitando mudanças de carreira. Segundo Ramos e Joia (2014), o turn-away de profissionais pode ser causado por insatisfação profissional devido à exaustão e às exigências do trabalho. Igualmente, a questão da dificuldade de crescimento dentro das empresas provoca o descontentamento com a área de atuação, que é 
diferente do descontentamento com o trabalho ou com o emprego.

Os dois artigos em questão exploram o ramo da TI (Tecnologia da Informação) a partir das histórias de carreira dos participantes da pesquisa e suas insatisfações com as escolhas profissionais anteriores. $\mathrm{O}$ termo turn-away foi mencionado em ambas como uma resposta à dificuldade dos indivíduos em adquirirem crescimento profissional. No caso de um dos estudos, o foco foi apresentar a insatisfação e a intenção de turn-away causadas pela exaustão e insatisfação com o trabalho, bem como pela necessidade dos profissionais de adquirirem novas experiências para se manterem mais atrativos no mercado de trabalho e crescerem profissionalmente (Mangia \& Joia, 2015). O outro estudo evidenciou que os profissionais da área de TI precisam de mais oportunidades de crescimento do que as empresas são capazes de oferecer ou do que é possível oferecer dentro de uma área técnica. Também pontuou que o desejo dos profissionais de mudarem de área não está tanto ligado à insatisfação com as atividades, mas sim com a uma busca por atividades mais interessantes e diferentes, bem como por novos desafios e experiências. Dessa forma, empresas interessadas em reter esses profissionais deveriam proporcionar-lhes esses tipos de oportunidade (Magia \& Joia, 2014).

Outro artigo analisado foi escrito por Veloso e Dutra (2011). Nele revelam-se importantes os atos de promoção de ações educativas, reflexões sobre o contexto e o autoconhecimento para os processos de gerenciamento de carreira dos profissionais. Nesse caso, o mundo organizacional provoca exigências sobre as competências dos trabalhadores devido à alta competitividade, o que tende a estimular a reflexão sobre a carreira e sua gestão, podendo levar a um plateau na carreira. Esse conceito se refere ao momento em que o trabalhador vê as suas atividades com desinteresse, não percebendo maneiras de ampliar suas responsabilidades e desenvolver seus conhecimentos e habilidades (Palacios \& Peixoto, 2015).

Ao atingirem esse momento, alguns profissionais procuram uma carreira acadêmica buscando fugir da competitividade do mercado de trabalho corporativo em função da crença de que a academia é distanciada de tal mercado. Todavia, percebem que o espaço acadêmico tem um diferente tipo de competitividade, a individual: cada professor trabalha por si e, muitas vezes, é difícil de lidar com as obrigações. Conforme o artigo produzido por Oliveira, Kilimnik e Oliveira (2013), um professor novo muitas vezes não é orientado e não existem planejamentos estratégicos destinados a auxiliá-lo no início de sua carreira. Ainda, em alguns casos, as avaliações de desempenho são realizadas por alunos, o que pode tornar o cenário acadêmico ainda mais complexo.

Todos os artigos sobre transição mercadomercado encontrados nessa revisão têm como foco profissionais de uma mesma área. Essa característica pode trazer implicações práticas positivas, uma vez que propicia bases a determinados gestores e orientadores de carreira para contextualizarem suas ações com populações específicas de profissionais. No entanto, entende-se 
que há uma limitação em descrever a maneira como os profissionais enfrentam as transições, visto que seria necessário considerar as exigências da etapa de vida pela qual estão passando os profissionais (adultez jovem ou adultez madura), além do momento de vida particular dos indivíduos, de maneira a contemplar os diferentes papéis e pilares que se fazem presentes e são relevantes para sua transição.

\section{Discussão}

Atualmente, as carreiras deixaram de ser lineares, tornando-se representações das decisões tomadas pelos indivíduos nos contextos de suas vidas e dos ambientes em que estão inseridos (Savickas, 2012). Com o rompimento da linearidade e com o menor vínculo do trabalhador com o emprego, as pessoas passaram a se deparar com transições, sendo elas planejadas, repentinas ou ainda "a espera de acontecer" (Lassance \& Sarriera, 2012). Em decorrência dos rompimentos de carreiras, os indivíduos mobilizam seus recursos pessoais e profissionais com o intuito de desempenhar novos papéis em novas situações. Mark Savickas vem aprimorando as proposições teóricas de Donald Super, defendendo que as carreiras dependem em grande parte de quem as conduz. A partir desse entendimento, é possível compreender a existência de uma carreira subjetiva, caracterizada pela atribuição de significados pelos indivíduos que as vivem de acordo com as experiências pessoais que têm (Savickas, 2013). Dois exemplos, explorados neste artigo, são as transições planejadas da universidade para o mercado de trabalho e planejadas ou não planejadas entre empregos ou da situação de ocupação para a de desocupação no mercado de trabalho.

A partir do término da graduação, os indivíduos perdem o status de estudantes e começam a atuar no papel de trabalhadores (Bardagi \& Boff, 2010). A transição entre universidade e mercado de trabalho envolve muitas expectativas por partes dos estudantes universitários em função da nova fase da vida que está por vir. Atualmente, conseguir ingressar no mercado de trabalho envolve diversas características pessoais e redes de contatos, e não apenas um diploma. É neste tipo de transição que o jovem tem a oportunidade de se experienciar nas diferentes possibilidades em sua profissão e, nesse caso, a qualidade da transição entre a universidade e o mercado de trabalho está diretamente associada ao comprometimento do aluno com o curso que está realizando (Teixeira \& Gomes, 2004). A universidade é considerada um ambiente seguro onde é possível obter o aprofundamento teórico para embasar a prática profissional. Em função disso, em muitas ocasiões, uma das dificuldades encontradas pelos jovens é que a prática realizada dentro do meio acadêmico se difere da prática realizada fora da universidade, fato que torna a transição mais difícil (Gomes \& Oliveira, 2004).

A partir de um estudo qualitativo realizado por Teixeira e Gomes (2004) com formandos dos cursos de Farmácia e Odontologia, tem-se que os estudantes, durante a universidade, vivenciam algumas situações, como a competitividade e a divergência de opiniões, que os deixam mais 
preparados para a vida profissional. Outra questão relevante no estudo é a insegurança dos formandos em relação ao sucesso profissional e ao ingresso no mercado de trabalho. Nesse caso, os alunos apresentaram preocupação com a transição para o mercado apenas no último ano de faculdade (Teixeira \& Gomes, 2004). Ainda, os resultados de uma pesquisa realizada por Neiva (1996) indicam que a dificuldade de inserção no mercado de trabalho afeta de forma negativa os estudantes que estão se preparando para vivenciar a transição (Neiva, 1996).

Os estudantes em fim de curso podem demonstrar otimismo em relação à inserção no mercado, embora não tenham um planejamento de carreira com objetivos e estratégias definidas (Teixeira, 2002). Esse dado sugere, segundo o autor, uma tendência a minimizar as dificuldades envolvidas nesse processo, possivelmente como um processo psicológico de autorregulação que visa a manter a autoestima e a motivação para enfrentar a transição para o mercado de trabalho. No entanto, cabe ressaltar que a vivência dessa transição toma uma dimensão maior do que a simples passagem do ambiente universitário para o mercado de trabalho, podendo ser considerada também, por vezes, a ser uma transição de identidade (Teixeira, 2004), que nesse texto é referenciada como sinônimo de autoconceito. A tarefa evolutiva necessária nesse período envolve uma revisão de autoconceito (fase de exploração), com o objetivo de redimensionar a percepção de si de acordo com a etapa do desenvolvimento (vida adulta), e com o papel de trabalhador, combinado ao significado pessoal que carrega.

Tal mudança na organização de papéis de vida pode ser encarada como uma dificuldade, tendo em vista o aumento da demanda de investimento no papel de trabalhador, no qual lhe será exigido maior autonomia e iniciativa em comparação com o papel de estudante que, muitas vezes, permite-o uma postura mais passiva (Silva \& Teixeira, 2013). Essa situação pode ser mais evidente no caso dos estudantes tradicionais, que se dedicam exclusivamente à vida acadêmica e não trabalham durante a graduação. As características dos alunos, que chegam à transição da universidade para o mercado, estão associadas à qualidade da experiência acadêmica como um todo e, por isso, a adaptação à universidade, que pode ser entendida como um período de transição do ensino médio para a universidade, é um componente relevante para o desenvolvimento de carreira do universitário. Sabe-se que as experiências vividas no primeiro ano de curso dependerão de expectativas prévias sobre a universidade e a profissão, as quais podem desencadear a percepção da experiência acadêmica como um desafio ou como uma oportunidade de crescimento pessoal e desenvolvimento profissional, bem como podem suscitar uma insatisfação com o curso e com a profissão (Teixeira, Dias, Hastenpflug \& Oliveira, 2008).

Os pontos que precisam ser considerados em relação à intenção de uma mudança de carreira no mercado são: o desejo de felicidade e a satisfação no trabalho. É necessário que os profissionais 
avaliem os motivos das transições e procurem as melhores qualificações, buscando atuar nas áreas que trarão maior destaque, a fim de que o processo faça sentido (Deis, 2015). Porém, não se deve esquecer de avaliar as oportunidades no mercado de trabalho para que sejam compatíveis com a intenção do profissional. Igualmente, são considerados fundamentais os fatores do ambiente social (como a economia e o mercado de trabalho) em indivíduos que estão buscando novas oportunidades, visto que esses fatores externos não são passíveis de controle pela própria pessoa e, assim, acabam afetando as decisões de buscas de emprego contemporâneas (Abbad \& Meneses, 2004). Para que se tenha maior controle desses fatores ambientais, é importante gerenciar a própria carreira, ou seja, realizar pesquisas de mercado, atualizar o networking, investigar possibilidades, fazer cursos.

Comparando com estudos internacionais, uma pesquisa longitudinal realizada na Finlândia, com 497 participantes, buscou identificar quais fatores pessoais e ambientais refletem em engajamento no trabalho. Outra contribuição do estudo identificou valores intrínsecos de carreira como recursos pessoais que contribuem em um maior engajamento na transição para o trabalho (Sorthex et al., 2013). Assim, a experiência de engajamento indica a adaptação à nova situação de vida e reflete a interação entre as características pessoais e os recursos disponíveis no ambiente (Bakker, Demerouti \& Schaufeli, 2003; Hakanen et al., 2006). Os resultados da pesquisa proposta por Konstam et. al. (2015) revelaram que adultos jovens, com maiores níveis de controle e confiança, apresentaram maior satisfação pessoal. Isso mostra a relevância da adaptabilidade de carreira durante um processo de transição e a necessidade de autogerenciamento do desenvolvimento profissional.

Apenas um dos artigos da revisão tem como objeto de estudo uma transição não planejada, a qual o sujeito não espera passar. Um evento como uma demissão, por exemplo, na maioria das vezes, não permite que o indivíduo se prepare para enfrentar os desafios que surgem. A transição inesperada é mais complexa em relação às demais, pois só poderá ser avaliada posteriormente (Schlossberg, 1989). A maneira com que se realizam as transições pode ter relação com a fase do ciclo vital em que o sujeito se encontra, o que torna possível, certas vezes, que as consequências de uma transição estejam relacionadas ao momento vivido pelo indivíduo. A transição à espera de acontecer ou antecipada pode ser percebida nos estudantes que estão concluindo a graduação e ingressando no mercado de trabalho, momentos em que são possíveis fazer uma análise das possibilidades existentes.

Os demais artigos referem-se às transições antecipadas, nas quais o indivíduo detém maior controle das situações, podendo explorar de forma planejada os ambientes em que está inserido e, também, as situações futuras. A transição da universidade para o mercado de trabalho é um exemplo dessa transição, na qual, muitas vezes, o indivíduo passa por mudanças de identidade e percepções a respeito de si em decorrência da etapa 
de desenvolvimento em que se encontra (Sampaio \& Teixeira, 2013). Por fim, fala-se também em carreiras sem fronteiras, as quais referem-se às relações dos indivíduos com a organização no contexto atual de competitividade e consequente necessidade de agilidade e flexibilidade. Esse conceito se adapta a uma relação interdependente e transacional entre organização e colaborador, na qual cabe ao trabalhador a responsabilidade pelo desenvolvimento do conhecimento e, igualmente, das habilidades necessárias para uma movimentação profissional (Defillipi \& Arthur, 1994). Nesse caso, é possível fazer relação com o conceito de carreira contemporânea, uma vez que as pessoas, hoje, podem assumir múltiplas funções e papéis no trabalho, sendo mais ativos e autônomos no processo. Além disso, quando os estudantes em transição de universidade para o mercado ingressam, de fato, no mundo do trabalho, novas competências e habilidade lhe são exigidos para estabelecerem-se ou buscarem novas alternativas de carreira, o que reforça a ideia da carreira sem fronteira.

A análise dos resultados demonstrou que os artigos analisados que abordam a transição mercado-mercado não tiveram como base a teoria construtivista de carreira (Savickas 2002, 2013), nem o modelo de recursos para a transição (4Ss) de Schlossberg (Schlossberg, Waters \& Goodman, 1995), sendo observada tal articulação com essas referências apenas nos estudos sobre a transição universidade-mercado. Também foi possível perceber que as transições de carreira de adultos na sua maioria estão fundamentadas pela área da psicologia organizacional, fato que torna a área de carreira um campo fértil para futuras investigações. Tal característica pode indicar que as pesquisas nacionais não se mostram teoricamente articuladas com a produção internacional, a qual concebe as transições como eventos inerentes ao desenvolvimento de carreira.

Desse modo, espera-se, com esse artigo, resumir e atualizar o que já foi estudado sobre o fenômeno de transição de carreira na literatura nacional. Os achados das pesquisas analisadas contribuíram para demonstrar a importância da adaptabilidade de carreira em universitários, identificando principalmente a necessidade de construir autoconfiança e indicando a busca de maior satisfação no trabalho como um fator importante para os profissionais planejarem transições. É possível verificar a relevância do autoconhecimento e do comprometimento com a carreira, contribuindo não somente na tomada de decisão durante a transição, mas também em escolhas mais satisfatórias na vida pessoal do indivíduo.

Com as limitações encontradas, almeja-se estimular futuros estudos, especialmente brasileiros, sobre o assunto a fim de que o conhecimento na área seja ampliado e mais qualificado. Assim, profissionais da área de carreira, que trabalham com orientação, planejamento ou aconselhamento, podem ter referências mais apropriadas e embasadas teoricamente para as suas práticas, podendo auxiliar de modo mais eficaz os indivíduos que estão passando ou passarão por transições de carreira, sejam elas planejadas ou não. 
Porém, já que o estudo aborda somente artigos nacionais, sugere-se que outra revisão de literatura possa ser realizada, contemplando artigos de outros países e contextos, para que possa ser possível conhecer outras realidades e comparar os resultados encontrados de forma mais detalhada.

\section{Referências}

Meneses, P. P. M. (2004). Lócus de controle: validação de uma escala em situação de treinamento. Brasília: Estudos de Psicologia, 9(3), 441-450. doi: 10.1590/S1413294X2004000300006

Bakker, A. B., Demerouti, E., \& Schaufeli, W. B. (2003). Dual Processes at Work in a Call Centre: An Application of the Job Demands-Resources Model. European Journal of Work and Organizational Psychology, 12, 393417.

Balassiano, M., \& Costa, I. S. A. (2006). Introdução. In M. Balassiano \& I. S. A. Costa (Orgs.). Gestão de carreiras: dilemas e perspectivas (pp. 17). São Paulo: Editora Atlas S/A.

Bardagi, M. P., \& Boff, R. M. (2010). Autoconceito, auto-eficácia profissional e comportamento exploratório em universitários concluintes. Avaliação: Revista da Avaliação da Educação Superior (Campinas), 15(1), 41-56. doi: 10.1590/S1414-40772010000100003

Barros, A. J. S., \& Lehfeld, N. A. S. (2007). Fundamentos de Metodologia Científica (3a ed.). São Paulo: Prentice-Hall. .

Baruch, Y., Szúcs, N., \& Gunz, H. (2015). Career Studies in Search of Theory: the Rise and
Rise of Concepts. Career Development International, 20(1), 3-20. doi: 10.1108/CDI11-2013-0137

Bedin, L. L., Sarriera, J. C., \& Paradiso, A. C. (2013). Desenvolvimento de carreira em psicólogos: tarefas evolutivas de estabelecimento. Revista Brasileira de Orientação Profissional, 14, 87-98.

Dieese. Rotatividade setorial: dados e diretrizes para a ação sindical. São Paulo: Dieese, 2014. Recuperado de http://www.dieese.org.br/livro/2014/rotati vidadeSetorial.pdf

Deffilipi, R. J., \& Arthur, M. B. (1994). The Boudaryless Career: a Competency-Based Perspective. Journal of Organizational Behavior, (15), 307-324.

Göks, A., \& Lassance, M. C. P. (1997). Formação da identidade profissional em estudantes universitários: as trajetórias acadêmicas (pp.369). Anais 9. IX Salão de Iniciação Cientifica da UFRGS. Porto Alegre, RS: UFRGS.

Gomes, A. M. T., \& Oliveira, D. C. (2004). Formação profissional e mercado de trabalho: um olhar a partir das representações sociais de enfermeiros. Revista Enfermagem, UERJ, 12(3), 265-271.

Hakanen, J., Bakker, A. B., \& Schaufeli, W. B. (2006). Burnout and Work Engagement among Teachers. Journal of School Psychology, 43, 495-513.

Hochman, B., Nahas, F. X., Oliveira, Filho R. S., \& Ferreira, L. M. (2005). Desenhos de 
pesquisa. Acta Cirúrgica Brasileira, 20(2), 2-9. doi: 10.1590/S0102-86502005000800002

Instituto Brasileiro de Geografia e Estatística (2016). Pesquisa Nacional por Amostra de Domicílios Contínua - Divulgação Trimestral. Recuperado de https://sidra.ibge.gov.br/pesquisa/pnadct/ tabelas.

Kilimnik, Z. M., \& Rodrigues, S. B. (2000). Trajetórias, transições e âncoras de carreiras: um estudo comparativo e de recursos humanos. Organizações e Sociedade, 7(17), 145171. doi: 10.1590/S198492302000000100012

Konstam, V., Demirtas, S. C., Tomek, S., \& Sweeney, K. (2015). Career Adaptability and Subjective Well-Being in Unemployed Emerging Adults. A Promising and Cautionary Tale. Journal of Career Development, 42(6), 1-15. doi: $10.1177 / 0894845315575151$.

Lassance, M. C., \& Sparta, M. (2003). A orientação profissional e as transformações no mundo do trabalho. Revista Brasileira de Orientação Profissional, 4(1/2), 13-19.

Lassance, M. C. P., \& Sarriera, J. C. (2012). Saliência do papel de trabalhador, valores de trabalho e desenvolvimento de carreira. Revista Brasileira de Orientação Profissional, 13(1), 4961.

Levinson, D. (1977). The Seasons of a Man's Life. New York: Alfred A. Knoff.

Magalhães, M. O., \& Teixeira, M. A. P. (2013). Antecedentes de comportamentos de busca de emprego na transição da universidade para o mercado de trabalho. Psicologia: Teoria e Pesquisa, 29(4), 411-419.

Magalhães, M. O. (2013). Propriedades Psicométricas da versão brasileira da escala de comprometimento com a carreira. Psicol. cienc. prof., 33(2). 303-317.

Mangia, U. B., \& Joia, L. A. (2015). Antecedentes à transição de carreira dos profissionais de Tecnologia da Informação. Revista de Administração, 50(4), 541-560. doi: $10.5700 /$ rausp1218

Neiva, K. (1996). Fim dos estudos universitários: efeitos das dificuldades do mercado de trabalho na representação do futuro profissional e no estabelecimento de projetos pós-universitários dos estudantes. Psicologia USP, 7(1-2), 203-224. doi: 10.1590/S1678-51771996000100010

Oliveira, L. C. V., Kilimnik, Z. M., \& Oliveira, R. P. (2013). Da gerência para a docência: metáforas do discurso de transição. Revista Eletrônica de Administração, Porto Alegre. 75(2), 301-329. doi: 10.1590/S141323112013000200002

Pauli, R. C., Nakabashi, L., \& Sampaio, A. V. (2012). Mudança estrutural e mercado de trabalho no Brasil. Revista de Economia Política, 32(3), 459-478. doi: 10.1590/S010131572012000300007

Puente, P. K., \& Peixoto, A. L. A. (2015). Ferramentas de diagnóstico para organizações e trabalho - um olhar a partir da Psicologia. Ed. Artmed. 
Ramos, E. A. A., \& Joia, L. A. (2014). Uma investigação acerca do fenômeno do turnaway entre os profissionais de tecnologia da informação. Revista Administração Mackenzie. São Paulo, 15(4). doi: 10.1590/167869712014/administracao.v15n4p75-109

Rueda, F. J. M., Martins, L. J., \& Campos, K. C. L. (2004). Empregabilidade: o que os alunos universitários entendem sobre isso? Psicologia: Teoria e Prática, 6(2), 63-73.

Savickas, M. L. (1997). Career Adaptability: An Integrative Construct for Life-Span, LifeSpace Theory. The Career Development Quarterly, 45(3), 247-259. doi: 10.1002/j.2161-0045.1997.tb00469.x

Savickas, M. L. (2002). Career Construction: A Developmental Theory of Vocational Behavior. In D. Brown (Org.). Career Choice and Development (4a ed., pp. 149-205). San Francisco, CA: John Wiley \& Sons.

Savickas, M. L. (2012). Life Design: A Paradigm for Career Intervention in the 21st Century. Journal of Counselingand Development, 90(1), 1319. doi: 10.1111/j.1556-6676.2012.00002.x

Savickas, M. L. (2013). Career Construction Theory and Practice. In R. W. Lent \& S. D. Brown (Eds.). Career Development and Counseling: Putting Theory and Research to Work (2a ed., pp. 147-183). Hoboken, New Jersey: John Wiley \& Sons.

Savickas, M. L., \& Baker, D. B. (2005). The History of Vocational Psychology: Antecedents, Origin, and Early Development. In W. B. Walsh \& M. L. Savickas (Ed.). Handbook of
Vocational Psychology (3a ed., pp. 15-49). Mahwah, NJ: Lawrence Erlbaum Associates Schlossberg, N. K. (1981). A Model for Analyzing Human Adaptation to Transition. The Counseling Psychologist, 9(2), 2-18. doi: 10.1177/001100008100900202

Schlossberg, N. K. (1989). Overwhelmed: Coping with Life's Ups and Downs (2a ed.). Lexington, Massachusetts: Lexington Books. Schlossberg, N. K., Waters, E. B., \& Goodman, J. (1995). Counseling Adults in Transition: Linking Practice with Theory (2a ed.). New York: Spring.

Schreiner, M. (2012). Donald Super Career Counseling Theory. CareenCounseling.

Silva, C. S. C., \& Teixeira, M. A. P. (2013); Experiências de estágio: contribuições para a transição universidade-trabalho. Paidéia, 23(54), 103-112. doi: 10.1590/198243272354201312

Soares, A. B., Francischetto, V., Dutra, B. M., Miranda, J. M., Nogueira, C. C., Leme, V. R., Araújo, A. A. M., \& Almeida, L. S. (2014). O impacto das expectativas na adaptação acadêmica dos estudantes no Ensino Superior. Psico USF., 19(1). doi: 10.1590/S1413-82712014000100006

Sortheix, F.M., Dietrich, J., Chow, A., \& SalmelaAro, K. (2013). The Role of Career Values for Work Engagement During the Transition to Working Life. Journal of Vocational Behavior, 83(3), 466-475. doi:10.1016/j.jvb.2013.07.003 
Super, D. E. (1980). A Life-Span, Life-Space Approach to Career Development. Journal of Vocational Behavior, 16(3), 282-298. doi: 10.1016/0001-8791(80)90056-1.

Super, D.; Savickas, M. \& Super, C. M. (1996). The Life-Span, Life-Space Approach to Careers. In D. Brown \& L. Brooks (Eds.). Career Choice and Development (3a ed., pp. 122-178). San Francisco: Jossey-Bass.

Teixeira, M. A. P. (2002). A experiência de transição entre a universidade e o mercado de trabalho. Tese de doutorado, Universidade Federal do Rio Grande do Sul.

Teixeira, M. A. P., Dias, A. C. G., Wottrich, S. H., \& Oliveira, A. M. (2008). Adaptação à universidade em jovens calouros. Psicologia Escolar e Educacional, 12(1), 158-202. doi: 10.1590/S1413-85572008000100013

Teixeira, M. A. P., \& Gomes, W. B. (2004). Estou me formando... e agora? Reflexões e perspectivas de jovens formandos universitários. Revista Brasileira de Orientação Profissional, 51(1), 47-52.

Teixeira, M. A., \& Silva, C. S. C. (2013). Experiências de estágio: contribuições para a transição universidade-trabalho. Paidéia, 23(54), 103-112. doi: 10.1590/198243272354201312

Vasconcellos, D. I. C., Andrade, A., Lima, M. B. N., \& Viana, R. P. M. (2005). Determinantes na transição de carreira no tênis: o caminho para o circuito profissional. Revista Digital, Buenos Aires, 91.
Veloso, E. F. R., \& Dutra, J. S.(2011). Carreiras sem fronteiras na gestão pessoal da transição profissional: um estudo com ex-funcionários de uma instituição privatizada. Revista de Administração Contemporânea, 15(5), 834-854. doi: 10.1590/S1415-65552011000500004

Veriguine, N. R., Krawulski, E., D Avila, G. T., \& Soares, D. H. P. (2010). Da formação superior ao mercado de trabalho: percepções de alunos sobre a disciplina orientação e planejamento de carreira em uma universidade federal. Revista Electrónica de Investigación y Docencia, 79-96.

Recebido em 23/02/2017

Aprovado em 03/08/2017 